\title{
Body Fluid or Substance
}

National Cancer Institute

\section{Source}

National Cancer Institute. Body Fluid or Substance. NCI Thesaurus. Code C13236.

Material produced by living organisms; it can be a necessary constituent of, or product of an organismal process. 